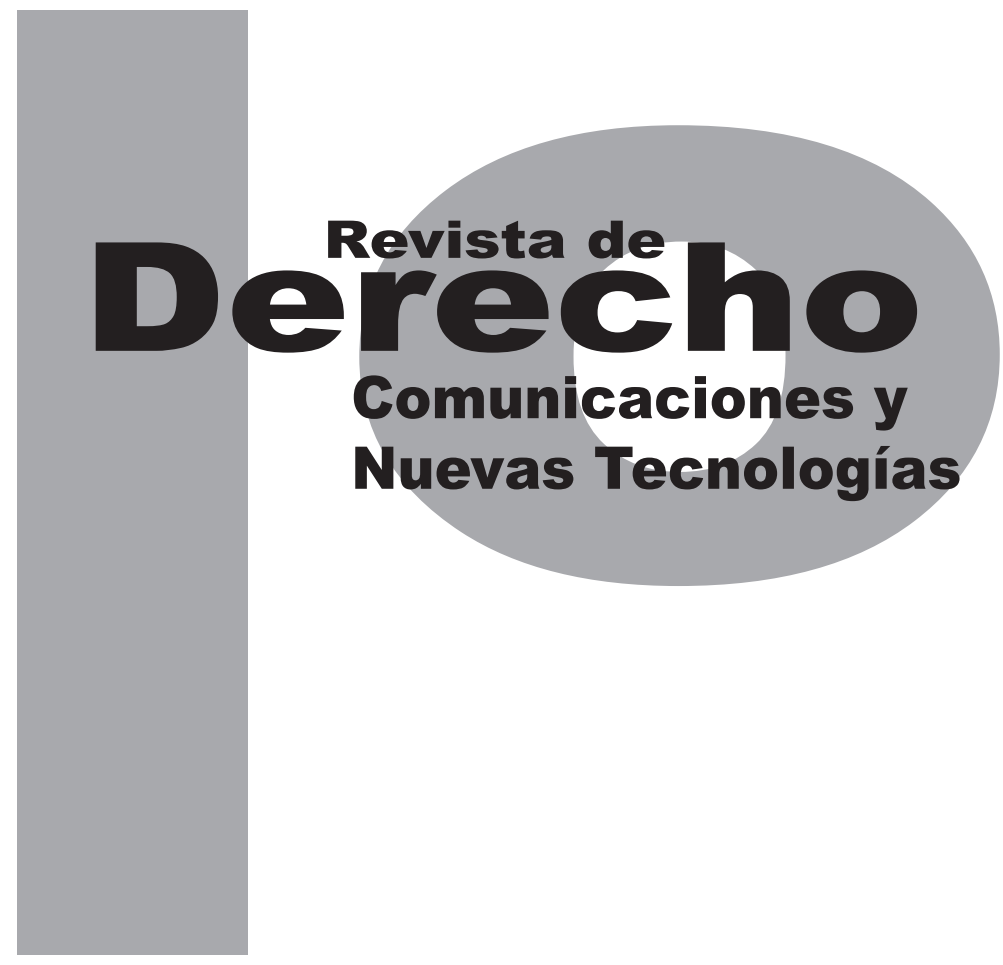

\title{
DEL DERECHO AL ACCESO A LA INFORMACIÓN AL DERECHO A LA PROTECCIÓN DE DATOS, EL CASO MEXICANO
}

Manuel M. Tenorio Adame

Universidad de los Andes

Facultad de Derecho

Revista de Derecho, comunicaciones y Nuevas Tecnologías

N. ${ }^{\circ}$ 7, Junio de 2012. ISSN 1909-7786 


\title{
Del derecho al acceso a la información al derecho a la protección de datos, el caso mexicano
}

\author{
Manuel M. Tenorio Adame ${ }^{1}$
}

\section{RESUMEN}

El presente artículo tiene el objetivo de presentar la transición del derecho al acceso a la información al derecho de protección de datos personales en México. En la medida en que se entienda esa transición se comprenderán los núcleos fundamentales de ambos derechos $y$ con ello sus alcances jurídicos. Además, el desarrollo de los derechos en la transición antes mencionada está inscrito en la perspectiva de Ios roles del Estado, los particulares y las personas bajo la teoría general de los derechos humanos. El presente ensayo se limita a realizar un estudio en el marco de la legislación correspondiente así como de criterios judiciales.

Palabras clave: derecho de acceso a la información y a la protección de datos personales.

\begin{abstract}
The present article has the objective to display the transition of the right to the access to the information to the right of protection of personal data in Mexico. Insofar as it is understood that transition the fundamental nuclei of both rights will be included in this way and their legal reaches. In addition, the development of the rights in the transition indicated above is enrolled in the prospect of the rolls of the State, the individuals and the people under the general theory of the human rights. The present test is limited within the framework to realise a study of the corresponding legislation as well as of judicial criteria.
\end{abstract}

Keywords: right to the access to the information and right of protection of personal data in Mexico.

\footnotetext{
Licenciado por la Universidad Anahuac del Norte de México. Diplomado en derecho norteamericano por Georgetown University, y en derechos humanos por el Instituto Internacional de Derechos Humanos (Estrasburgo, Francia). Especialista en derechos humanos por la Universidad Complutense de Madrid, y en ciencia política y derecho constitucional por el Centro de Estudios Políticos y Constitucionales de Madrid (España). Diploma de estudios avanzados por la Facultad de Derecho de la Universidad Complutense de Madrid. Doctor en estudios superiores de derecho constitucional por la Universidad Complutense de Madrid. Ha impartido cátedra en distintas universidades de México entre las que se destacan la Universidad Anahuac y el Tecnológico de Monterrey. Exdirector de la unidad de enlace de acceso a la información pública y protección de datos de la Procuraduría General de la República (México). En la actualidad, docente investigador del Instituto Latinoamericano de la Comunicación Educativa y socio de Data \& TIC consultores en derecho, información y tecnología. Correo electrónico: dr.tenorioadame@gmail.com
} 


\section{SUMARIO}

I. Un planteamiento a través del estado, particulares y personas en el manejo de la información - ii. El derecho de acceso a la información. El papel del estado como garante, contenedor y usuario de la información y su incidencia en la protección de datos personales - iii. El derecho a la protección de los datos personales y los particulares como contenedores y usuarios de la información - iv. Una conclusión a través del ejercicio de las personas, de los derechos de acceso a la información y a la protección de datos - fuentes. 
I. UN PLANTEAMIENTO A TRAVÉS DEL ESTADO, PARTICULARES Y PERSONAS EN EL MANEJO DE LA INFORMACIÓN

En el antiguo Parlamento británico se acuñó la expresión lapidaria "cuarto poder" cuando se referían al ejercicio del derecho a la información por parte de los periodistas. Esta inercia en el manejo de la información sufrió una metamorfosis y en plena guerra fría se creó la frase "quien tiene la información, tiene el poder". Después de la caída del muro del Berlín y el advenimiento real de la cultura de los derechos humanos en los países de Latinoamérica, se comprendió que el acceso a la información está incluido dentro de las reivindicaciones del Estado democrático y de derecho a que estas naciones se adhieren en sus distintas vertientes.

A partir de esta idea de cambio en la concepción sobre el manejo del acceso a la información se han venido construyendo tres grandes grupos de interesados en el manejo de la información que de alguna u otra forma convergen, a saber:

1. El Estado como garante, contenedor y usuario de información.

2. Los particulares como contenedores y usuarios de información; $y$,

3. Las personas en el ejercicio del derecho fundamental de acceso a la información.

Estas tres agrupaciones se abordan dentro de la teoría de los derechos humanos o fundamentales a partir del derecho de acceso a la información y protección de datos personales, a través de las vertientes legislativa y jurisprudencial. La división que se propone en el presente ensayo tiene un peso específico en la noción del derecho de acceso a la información y protección de datos, pues, como se advertirá, dependiendo de quién esté manejando la información será el planteamiento jurídico a que haya lugar.

El catálogo tripartito de interesados en el manejo de la información que se plantea es de trascendental referencia por las singularidades que toma y seguirá tomando la información. Para demostrarlo enunciaremos el caso mexicano y la manera específica en que el derecho humano de acceso a la información muta al derecho fundamental a la protección de datos personales, y cómo a través de estos cambios en el derecho de acceso a la información han creado especificaciones jurídicas de relevancia singular, que inciden de manera directa en la protección de datos personales.

Por lo anterior habrá que mencionar brevemente el papel de cada uno de los usuarios de la información para comprender el alcance y el rol de cada quien. El Estado, como garante, contenedor y usuario de la información, significa la organización jurídica y política más importante en cuanto al uso de la información. Por una parte está obligado a utilizarla bajo el principio de legalidad lo que lo ubica como contenedor y usuario; por otra parte, es el vigilante de que las distintas personas públicas y privadas utilicen la información en forma legal², tomando así el

2 En el caso colombiano, la Superintendencia de Industria y Comercio es la encargada de vigilar el uso que se haga de los datos personales; en el caso mexicano es el Instituto Federal de Acceso a la Información y Protección de Datos, mejor conocido por sus siglas IFAI. 
papel de juez y parte frente al acceso a la información, por lo que también adquiere responsabilidades singulares en la garantía, contención y manejo de la misma.

Los particulares - como contenedores y usuarios de información-, son las personas colectivas o individuales con personalidad jurídica reconocida por el derecho civil o comercial, que recolectan y usan la información ceñidos a la legalidad. Por ejemplo, los comerciantes que utilizan bases de datos para llegar a sus clientes, en un primer momento deben captar la información y procesarla lo que los convierte en contenedores; la utilización posterior de ésta con fines lícitos los hace usuarios de la información.

Las personas en ejercicio del derecho fundamental de acceso a la información y protección de datos simbolizan la unión de los dos grupos anteriores, más el postulado de los derechos humanos en lo concerniente al acceso a la información y protección de datos. Esto cobra sentido pues dentro de las normas de los derechos fundamentales el Estado sólo puede hacer lo que le está facultado por la norma, mientras que los particulares hacen lo propio, siempre y cuando no les esté prohibido. Estas dos vertientes contenidas en el principio de legalidad, forzosamente están incluidas en la tesis de los derechos humanos que, por supuesto, rigen el derecho de acceso a la información y protección de datos personales.

Así esta triple relación de tenedores y usuarios de las distintas clases de información converge en el campo de los derechos fundamentales y obliga a que el uso y contención de la información se lleve a cabo bajo el respeto de los derechos humanos reconocidos en la Constitución y en los tratados internacionales de los que el Estado mexicano sea parte, así como de las garantías para su protección. De esta suerte, su ejercicio no podrá restringirse ni suspenderse, salvo en los casos y bajo las condiciones que la misma ley fundamental establece, y contemplando los principios de universalidad, interdependencia, indivisibilidad y progresividad que consagra esta teoría. ${ }^{3}$

\section{EL DERECHO DE ACCESO A LA INFORMACIÓN. EL PAPEL DEL ESTADO COMO GARANTE, CONTENEDOR Y USUARIO DE LA INFORMACIÓN Y SU INCIDENCIA EN LA PROTECCIÓN DE DATOS PERSONALES}

El derecho de acceso a la información tiene como principio básico el que todos los documentos oficiales, en condiciones de igualdad y bajo el amparo de una normativa clara, son públicos; mientras que la negativa al acceso es una excepción a un derecho humano que ha de estar plenamente justificada en la norma. Luego, no se trata de asegurar la obligación de brindar la información que las autoridades deseen proporcionar, sino de garantizar un auténtico derecho a saber por parte de la ciudadanía para que esté bien informada sobre el correcto uso de sus derechos como corresponde a una sociedad democrática.

3 Contrástese el artículo $1^{\circ}$ de la Constitución Política de los Estados Unidos Mexicanos, disponible en http://www.diputados.gob.mx/ LeyesBiblio/ 
Por un lado, el Estado debe asegurar que cualquier ciudadano pueda tener acceso a documentos ${ }^{4}$ e información en poder de las autoridades que tengan el carácter de públicas (Ejecutivo, Legislativo, Judicial y demás órganos autónomos constitucionales), pues cualquier acto de gobierno puede originar una referencia informativa, una consulta social, una opinión pública o personal. Es decir, el Estado asume acciones que, participando de una o varias de las potestades anteriores, lo convierten específicamente en sujeto obligado del derecho a la información. Por otro lado, los particulares procesan y utilizan la información bajo los parámetros legales que les imponen diversas normas, por ejemplo, el secreto profesional, datos personales, etc.

En este marco, se estima pertinente esbozar esquemáticamente algunas funciones y responsabilidades del derecho de acceso a la información pública, desde la triple concepción de los tenedores de la misma, ya que este somero análisis da fe del efecto positivo y multiplicador que presenta su constante ejercicio:

1) Estado como garante, contenedor y usuario de información:

a. Reconoce y garantiza la opinión pública libre de las personas.

$4 \quad$ El artículo 3 de la Ley Federal de Acceso a la Información Pública Gubernamental establece que se deberá entender por documento: "Los expedientes, reportes, estudios, actas, resoluciones, oficios, correspondencia, acuerdos, directivas, directrices, circulares, contratos, convenios, instructivos, notas, memorandos, estadísticas o bien, cualquier otro registro que documente el ejercicio de las facultades o la actividad de los sujetos obligados y sus servidores públicos, sin importar su fuente o fecha de elaboración. Los documentos podrán estar en cualquier medio, sea escrito, impreso, sonoro, visual, electrónico, informático u holográfico. Para mayor información sobre la legislación mexicana consultar http://www.diputados.gob.mx/LeyesBiblio/ b. Controla la actividad administrativa.

c. Garantiza que la información se utiliza bajo el principio de legalidad.

d. Recolecta y custodia la información de acuerdo con parámetros legales.

e. Utiliza la información para la consecución de sus fines.

2) Particulares como contenedores y usuarios de información:

a. Recolección y custodia de la información según el tipo de información de que se trate (pública o privada), de acuerdo con parámetros legales.

b. Utilización de la información para sus objetivos de forma lícita.

c. Certeza en el manejo de la información que manejan por haber sido obtenida con parámetros adecuados a la norma.

3) Personas en el ejercicio del derecho fundamental de acceso a la información:

\section{a. Fomento y garantía de participación democrática.}

b. Ejercicio efectivo de derechos y libertades.

El derecho de acceso a la información se encuentra ligado estrechamente a la transparencia gubernativa, concepto de reciente cuño en la doctrina y la praxis de la Administración Pública en México; jurídicamente se caracteriza a partir 
de la teoría de los derechos y es tutelado por el artículo $6^{\circ}$ de la Constitución Política cuyos principios son:

I. Toda la información en posesión de cualquier autoridad, entidad, órgano y organismo federal, estatal y municipal, es pública y sólo podrá ser reservada temporalmente por razones de interés público en los términos que fijen las leyes. En la interpretación de este derecho deberá prevalecer el principio de máxima publicidad.

II. La información que se refiere a la vida privada y los datos personales será protegida en los términos y con las excepciones que fijen las leyes.

III. Toda persona, sin necesidad de acreditar interés alguno o justificar su utilización, tendrá acceso gratuito a la información pública, a sus datos personales o a la rectificación de éstos.

IV. Se establecerán mecanismos de acceso a la información y procedimientos de revisión expeditos. Estos procedimientos se sustanciarán ante órganos u organismos especializados e imparciales, y con autonomía operativa, de gestión y de decisión.

V. Los sujetos obligados deberán preservar sus documentos en archivos administrativos actualizados y publicarán a través de los medios electrónicos disponibles, la información completa y actualizada sobre sus indicadores de gestión y el ejercicio de los recursos públicos.
VI. Las leyes determinarán la manera en que los sujetos obligados deberán hacer pública la información relativa a los recursos públicos que entreguen a personas físicas o morales.

VII. La inobservancia a las disposiciones en materia de acceso a la información pública será sancionada en los términos que dispongan las leyes.

Los llamados derechos fundamentales son inherentes a las personas y, por tanto, positivizados en las constituciones como un reconocimiento de valores reconocidos por la Norma Suprema; por su parte, el papel de las leyes consiste en desarrollarlos en la medida que la Constitución y los tratados internacionales lo permitan. Tal reconocimiento se entiende que debe formar parte de los sistemas jurídicos nacionales o internacionales, en cuanto instrumento fundamental de la convivencia política.

La Declaración de los Derechos del Hombre y el Ciudadano (1789) reconoció, en el artículo XI, el derecho a la libertad de expresión, así:

"La libre comunicación de los pensamientos y las opiniones es uno de los derechos más preciosos del hombre: todo ciudadano puede entonces hablar, escribir e imprimir libremente, salvo su obligación de responder al abuso de esta libertad en los casos determinados por la ley."

Bajo esta afirmación, la libertad de expresión, desde entonces considerada de especial importancia, protegió al emisor o fuente de la información. Otro ejemplo de la positivización de este derecho se dio a mitad del siglo XX, con la 
Declaración Universal de los Derechos Humanos (1948), que proclamó en su artículo XIX:

"Todo individuo tiene derecho a la libertad de opinión; este derecho incluye el de no ser molestado a causa de sus opiniones, el de investigar y recibir informaciones y opiniones, y el de difundirlas, sin limitaciones de fronteras, por cualquier medio de expresión."

Adicionalmente, dicho derecho fue vigorizado por los tratados internacionales de derechos humanos, entre los que destacan la Convención Americana sobre Derechos Humanos, que en su artículo 13 dispone:

"Artículo 13. Libertad de Pensamiento y de Expresión

1. Toda persona tiene derecho a la libertad de pensamiento y de expresión. Este derecho comprende la libertad de buscar, recibir y difundir informaciones e ideas de toda índole, sin consideración de fronteras, ya sea oralmente, por escrito o en forma impresa o artística, o por cualquier otro procedimiento de su elección.

2. El ejercicio del derecho previsto en el inciso precedente no puede estar sujeto a previa censura sino a responsabilidades ulteriores, las que deben estar expresamente fijadas por la ley y ser necesarias para asegurar:

a. el respeto a los derechos o a la reputación de los demás, o

b. la protección de la seguridad nacional, el orden público o la salud o la moral públicas.
3. No se puede restringir el derecho de expresión por vías o medios indirectos, tales como el abuso de controles oficiales o particulares de papel para periódicos, de frecuencias radioeléctricas, o de enseres y aparatos usados en la difusión de información o por cualesquiera otros medios encaminados a impedir la comunicación y la circulación de ideas y opiniones.

4. Los espectáculos públicos pueden ser sometidos por la ley a censura previa con el exclusivo objeto de regular el acceso a ellos para la protección moral de la infancia y la adolescencia, sin perjuicio de lo establecido en el inciso 2.

5. Estará prohibida por la ley toda propaganda en favor de la guerra y toda apología del odio nacional, racial o religioso que constituyan incitaciones a la violencia o cualquier otra acción ilegal similar contra cualquier persona o grupo de personas, por ningún motivo, inclusive los de raza, color, religión, idioma u origen nacional."

El Pacto Internacional de los Derechos Civiles y Políticos a través de su artículo 19, estatuye:

“Artículo 19.

1. Nadie podrá ser molestado a causa de sus opiniones.

2. Toda persona tiene derecho a la libertad de expresión; este derecho comprende la libertad de buscar, recibir y difundir informaciones e ideas de toda índole, sin consideración de fronteras, ya sea oralmente, por escrito o en forma impresa o artística, o por cualquier otro procedimiento de su elección. 
3. El ejercicio del derecho previsto en el párrafo 2 de este artículo entraña deberes y responsabilidades especiales. Por consiguiente, puede estar sujeto a ciertas restricciones, que deberán, sin embargo, estar expresamente fijadas por la ley y ser necesarias para:

a. Asegurar el respeto a los derechos o a la reputación de los demás;

b. La protección de la seguridad nacional, el orden público o la salud o la moral públicas."

Resulta entonces que la libertad de expresión, en su concepción contemporánea, comprende cuatro libertades interrelacionadas: 1 ) Buscar; 2) Difundir, 3) Recibir información, y 4) Delimitar responsabilidades sobre el uso de esa información.

Ahora, por lo que toca al sistema jurídico mexicano, el Decreto publicado en el Diario Oficial del 6 de diciembre de 1977, reforma y adiciona, entre otros, el artículo $6^{\circ}$ de la Constitución Política, relativo a la obligación estatal de garantizar el derecho de acceso a la información. Antes dicho artículo hacía referencia solamente al derecho de libertad de expresión; con la reforma se incluyó de manera explícita: "el derecho a la información será garantizado por el Estado".

No obstante lo anterior, el país estaba lejos de ser un Estado de derecho a la altura de las exigencias y de las aspiraciones de la sociedad mexicana, como consecuencia de la desconfianza en las instituciones y la opacidad acumulada por años en sus actuaciones. Dicha desconfianza fue generada por la subcultura de la corrupción y de la impunidad en todas las áreas y en todos los órdenes del gobierno. En suma, carecíamos de una sólida cultura de la legalidad que fomentara el respeto y apego a la norma jurídica. Por consecuencia, el principio de legalidad no era robusto y, por ende, la teoría de los derechos humanos no cumplía con sus objetivos.

Uno de los principales pilares del Estado democrático y de derecho está en que el Gobierno cese de ser exclusivamente un vigilante de los derechos fundamentales del ciudadano y se empeñe en hacerlos efectivos, supliendo a través de la "materialización de la ley" los impedimentos de las personas que dentro de la sociedad no puedan ejercerlos. En este sentido, y a fin de que la Administración Pública del siglo XXI diera respuesta a las demandas y expectativas de la sociedad en materia de honestidad y legitimidad públicas, era necesario tener un gobierno capaz de transformar los esquemas tradicionales de información sobre la gestión pública.

El 12 de junio del año 2002 entró en vigor la Ley Federal de Transparencia y Acceso a la Información Pública Gubernamental (LFTAIPG). El propósito principal de la LFTAIPG es hacer que toda la información en poder de cualquier entidad pública esté accesible a cualquier persona, salvo ciertas excepciones generales, una de ellas, la información reservada. Ello se contempla en los artículos 1 y 2 en cuyo texto se refleja la regla general en materia de acceso a la información pública gubernamental, la cual fue tomada del propio artículo $6^{\circ}$ de la Constitución, 
antes mencionado. ${ }^{5}$ La información reservada es aquella que se encuentra fuera del acceso público por un periodo máximo de doce años, que se podrá ampliar a otro igual siempre y cuando cumpla con alguno de los requisitos establecidos en los artículos 13 y $14 .^{6}$

Es muy importante destacar, como se ha venido haciendo, que el derecho a la información no es absoluto, que puede limitarse siempre y cuando la limitación esté dentro del bloque de

5 El artículo $1^{\circ}$ de la Ley Federal de Transparencia y Acceso a la Información Pública Gubernamental establece: "La presente Ley es de orden público. Tiene como finalidad proveer lo necesario para garantizar el acceso de toda persona a la información en posesión de los Poderes de la Unión, los órganos constitucionales autónomos o con autonomía legal, y cualquier otra entidad federal". Mientras que el artículo $2^{\circ}$ de la ley en comento dispone: "Toda la información gubernamental a que se refiere esta Ley es pública y los particulares tendrán acceso a la misma en los términos que ésta señala. Para mayor facilidad sobre la consulta de la legislación mexicana se puede consultar http://www.diputados.gob.mx/LeyesBiblio/

6 El artículo 13 de la ley que se analiza, establece: "Como información reservada podrá clasificarse aquélla cuya difusión pueda: I. Comprometer la seguridad nacional, la seguridad pública o la defensa nacional; II. Menoscabar la conducción de las negociaciones o bien, de las relaciones internacionales, incluida aquella información que otros Estados $\mathrm{u}$ organismos internacionales entreguen con carácter de confidencial al Estado Mexicano; III. Dañar la estabilidad financiera, económica o monetaria del país; IV. Poner en riesgo la vida, la seguridad o la salud de cualquier persona, o V. Causar un serio perjuicio a las actividades de verificación del cumplimiento de las leyes, prevención o persecución de los delitos, la impartición de la justicia, la recaudación de las contribuciones, las operaciones de control migratorio, las estrategias procesales en procesos judiciales o administrativos mientras las resoluciones no causen estado. Por su parte el artículo 14 de la misma ley dispone: "También se considerará como información reservada: I. La que por disposición expresa de una Ley sea considerada confidencial, reservada, comercial reservada o gubernamental confidencial; II. Los secretos comercial, industrial, fiscal, bancario, fiduciario u otro considerado como tal por una disposición legal; III. Las averiguaciones previas; IV. Los expedientes judiciales o de los procedimientos administrativos seguidos en forma de juicio en tanto no hayan causado estado; V. Los procedimientos de responsabilidad de los servidores públicos, en tanto no se haya dictado la resolución administrativa o la jurisdiccional definitiva, o VI. La que contenga las opiniones, recomendaciones o puntos de vista que formen parte del proceso deliberativo de los servidores públicos, hasta en tanto no sea adoptada la decisión definitiva, la cual deberá estar documentada. Cuando concluya el periodo de reserva o las causas que hayan dado origen a la reserva de la información a que se refieren las fracciones III y IV de este Artículo, dicha información podrá ser pública, protegiendo la información confidencial que en ella se contenga. No podrá invocarse el carácter de reservado cuando se trate de la investigación de violaciones graves de derechos fundamentales o delitos de lesa humanidad." constitucionalidad de los derechos humanos, es decir dentro de la Constitución Política o en algún tratado internacional, tal y como lo indica el artículo $1^{\circ}$ de la ley fundamental mexicana. La limitación a los derechos fundamentales puede ser positivizada en la ley pero nunca ésta puede ir en contra de las normas constitucionales.

Los artículos 13 y 14 de la Ley Federal de Transparencia y Acceso a la Información Pública Gubernamental especifican las excepciones precisas que son autorizadas por mandato del bloque de constitucionalidad, en lo atinente a la información reservada.

Existe un segundo bloque de excepciones que analizaremos dentro del concepto de datos personales, conocido como información confidencial. En la excepción al derecho fundamental a la información bajo su vertiente de confidencialidad, se da la mutación del derecho de acceso a la información al de protección de datos personales.

Si como hasta ahora hemos visto, el derecho a la información puede ser limitado sí y solo sí la limitación se encuentra dentro del bloque de constitucionalidad, y considerando que existe otra clase de información que por sus características está enmarcada dentro del derecho a la protección de los datos personales, nos encontramos con la normativización de un derecho bajo dos vertientes: por un lado el derecho a la información que se refiere a la vida privada y los datos personales, los cuales serán protegidos en los términos y con las excepciones que fijen las leyes según el artículo $6^{\circ}$, y por otro lado el artículo 16 de la ley fundamental mexicana que 
establece el derecho a la protección de los datos personales, al acceso, rectificación, cancelación y oposición de los mismos.

Esta dualidad en la protección de datos es muy importante, y se explica a través de la evolución que ha tenido el derecho al acceso a la información y el derecho a la protección de datos personales. El primero fue constitucionalizado en el año 2007, mientras que el segundo debió esperar hasta el 2009 cuando se agregó el segundo párrafo del artículo 16 en la ley fundamental mexicana. Por lo tanto, en primera instancia, la esencia del derecho a la protección de datos personales se establece como una excepción al derecho de acceso a la información, y sólo mediante la segunda adición en comento fue concebido como patrimonio jurídico de sus titulares.

La anterior hipótesis toma sentido si analizamos los artículos 18 y 19 de la Ley Federal de Acceso a la Información Pública, que reglamentan el artículo $6^{\circ}$ de la Constitución mexicana, los cuales versan sobre la información de naturaleza confidencial y norman la excepción al derecho a la información a través de la protección a los datos personales. ${ }^{7}$

$7 \quad$ El artículo 18 de la ley en análisis dice: "Como información confidencial se considerará: I. La entregada con tal carácter por los particulares a los sujetos obligados, de conformidad con lo establecido en el Artículo 19, y II. Los datos personales que requieran el consentimiento de los individuos para su difusión, distribución o comercialización en los términos de esta Ley. No se considerará confidencial la información que se halle en los registros públicos o en fuentes de acceso público". Por su parte el artículo 19 establece: "Cuando los particulares entreguen a los sujetos obligados la información a que se refiere la fracción I del artículo anterior, deberán señalar los documentos que contengan información confidencial, reservada o comercial reservada, siempre que tengan el derecho de reservarse la información, de conformidad con las disposiciones aplicables. En el caso de que exista una solicitud de acceso que incluya información confidencial, los sujetos obligados la comunicarán siempre y cuando medie el consentimiento expreso del particular titular de la información confidencial." Para mayor facilidad
Así, los particulares encuentran en primera instancia, en la excepción al derecho al acceso a la información, la posibilidad de ejercitar el derecho a la protección de datos personales, con la salvedad de que el sujeto obligado a respetárselo es el Estado. En específico, cuando mencionamos al Estado como garante, contenedor y usuario de la información, nos referimos a que el Estado se debe regir por las normas constitucionales establecidas en el artículo $6^{\circ}$ de la Constitución Política y desarrolladas en la Ley Federal de Transparencia y Acceso a la Información Pública Gubernamental.

Por su parte, el pleno de la Suprema Corte de Justicia de la Nación, en la tesis aislada P. LX/2000, visible en la página 74 del Semanario Judicial de la Federación y su Gaceta XI, Novena Época, abril de 2000, ha establecido que el derecho a la información no es absoluto y que éste admite limitantes sobre todo cuando se trata de derechos de terceros, a saber: ${ }^{8}$

\section{DERECHO A LA INFORMACIÓN. SU EJERCICIO SE ENCUENTRA LIMITADO TANTO POR LOS INTERESES NACIONALES $Y$ DE LA SOCIEDAD, COMO POR LOS DERECHOS DE TERCEROS. El derecho a} la información consagrado en la última parte del artículo 6o. de la Constitución Federal no es absoluto, sino que, como toda garantía, se halla sujeto a limitaciones o excepciones que se sustentan, fundamentalmente, en la protección de la seguridad nacional y en el respeto tanto a los intereses de la sociedad como a

sobre la consulta de la legislación mexicana se puede consultar http:// www.diputados.gob.mx/LeyesBiblio/

8 Esta tesis aislada PLX/2000, también puede ser consultada en la base de datos de tesis y jurisprudencia IUS de la Suprema Corte de Justicia de la Nación bajo el número de registro 191967. 
los derechos de los gobernados, limitaciones que, incluso, han dado origen a la figura jurídica del secreto de información que se conoce en la doctrina como "reserva de información" o "secreto burocrático". En estas condiciones, al encontrarse obligado el Estado, como sujeto pasivo de la citada garantía, a velar por dichos intereses, con apego a las normas constitucionales y legales, el mencionado derecho no puede ser garantizado indiscriminadamente, sino que el respeto a su ejercicio encuentra excepciones que lo regulan y a su vez lo garantizan, en atención a la materia a que se refiera; así, en cuanto a la seguridad nacional, se tienen normas que, por un lado, restringen el acceso a la información en esta materia, en razón de que su conocimiento público puede generar daños a los intereses nacionales y, por el otro, sancionan la inobservancia de esa reserva; por lo que hace al interés social, se cuenta con normas que tienden a proteger la averiguación de los delitos, la salud y la moral públicas, mientras que por lo que respecta a la protección de la persona existen normas que protegen el derecho a la vida o a la privacidad de los gobernados.

Ahora bien, ¿cuál es la trascendencia del Estado como garante, contenedor y usuario de la información? La respuesta a esta pregunta adquiere un peso específico en materia de los derechos de acceso a la información y de protección de datos personales. Ambos derechos se rigen bajo el principio de legalidad y éste, a su vez, está inserto en la teoría de los derechos humanos, por lo que el Estado al actuar como garante, contenedor y usuario de la información debe guiarse forzosamente por este principio.
También se tendrá que delimitar de manera específica cuándo el Estado puede actuar como garante, contenedor o usuario, pues dependiendo de qué rol esté protagonizando será la normatividad que se imponga en un caso específico, es decir, no es lo mismo el Estado como árbitro y garante del acceso a la información y/o protección de datos personales, que como contenedor de la información de un documento que ha sido archivado y está bajo su custodia, o como usuario de la información recabada para la consecución de sus fines.

Lo anterior se puede demostrar mediante la tesis aislada $1^{\text {a }}$. CLXXXVIII/2009, emitida por la Primera Sala de la Suprema Corte de Justicia de la Nación, publicada en el Semanario Judicial de la Federación y su Gaceta XXX, de noviembre de 2009, página 401, que a la letra dice: ${ }^{9}$

ACTO DE MOLESTIA. LO CONSTITUYE LA TOMA DE FOTOGRAFÍAS A QUIENES NO TIENEN LA CALIDAD DE DETENIDOS O PRESUNTOS RESPONSABLES. La toma de fotografías a personas que no han sido puestas a disposición del Ministerio Público en calidad de detenidas o presuntas responsables -cuando éste sólo ha ordenado su localización y presentación- configura un acto de molestia porque menoscaba o restringe derechos de la persona, al hacer uso de su imagen, aunado a que la obtención de fotografías puede resultar violatoria de los derechos a la honra y a la dignidad contenidos en los artículos 17 del Pacto Internacional de Derechos Civiles y Políticos y 11 de la Convención Americana sobre Derechos Humanos, si el Estado incumple con sus

$9 \quad$ Este criterio puede ser consultado, además, en el sistema informático IUS de compilación de tesis y jurisprudencia de la misma Suprema Corte de Justicia de la Nación, bajo el número de registro 166037. 
obligaciones relativas a la protección de datos personales, las cuales consisten en: a) solicitar o registrar información que contenga datos personales sólo en los casos previstos por la ley; $y, b$ ) tratar confidencialmente tales datos, lo que implica utilizarlos o revelarlos sólo con el consentimiento de la persona a quien correspondan. Así, el hecho de que la autoridad obtenga fotografías de cualquier persona, sin importar su situación jurídica, efectivamente representa un menoscabo y un deterioro en sus derechos, de naturaleza continuada, pues mientras el resultado del acto (las fotografías) no se elimine, el acto de molestia continúa.

El anterior razonamiento judicial del máximo órgano facultado para ello, reafirma el criterio que hemos estado sosteniendo a lo largo del presente artículo respecto del papel del Estado como garante, contenedor y usuario de la información. Por una parte, el Estado para realizar sus funciones y objetivos necesita convertirse en contenedor y usuario de la información, mientras que, por la otra, se convierte en garante o rector de la utilización y contenido de la información, con lo cual califica estas tres acciones aunque sea el mismo Estado el sujeto que está conteniendo, utilizando o garantizando el manejo de la información.

La tesis en estudio advierte que el Estado debe cumplir con las obligaciones que tiene que seguir en materia de protección de datos personales, a saber: a. solicitar o registrar información que contenga datos personales sólo en los casos previstos por la ley; $y$,

b. tratar confidencialmente tales datos, lo que implica utilizarlos o revelarlos sólo con el consentimiento de la persona a quien correspondan.

Esta dualidad en las obligaciones que se le imponen al Estado encajan permanentemente el principio de legalidad: "solicitar o registrar información que contenga datos personales sólo en los casos previstos por la ley", con "la autoridad puede hacer solamente lo que le está permitido por la ley". Con respecto a los particulares, el principio que reza "Ios particulares pueden hacer todo lo que no les está prohibido", acopla con "tratar confidencialmente los datos, lo que implica utilizarlos o revelarlos sólo con el consentimiento de la persona", es decir, mientras que no exista obligación o prohibición alguna para entregar su información, ésta les debe de ser resguardada conforme indica la norma jurídica, de lo contrario atentaría contra las libertades públicas.

Hasta aquí hemos planteado la manera en que el Estado maneja la información como garante, contenedor y usuario de la misma. En el siguiente punto veremos el papel de los particulares como contenedores y usuarios de la información, en específico el papel que juega el derecho a la protección de los datos personales. 


\section{EL DERECHO A LA PROTECCIÓN DE LOS DATOS PERSONALES $Y$ LOS PARTICULARES COMO CONTENEDORES Y USUARIOS DE LA INFORMACIÓN}

Siguiendo el principio de legalidad, los particulares tienen derecho a acceder a información siempre y cuando no exista una restricción prevista en el bloque de constitucionalidad, la cual puede ser desarrollada a nivel secundario por las leyes.

La adición del segundo párrafo del artículo 16 de la Constitución Política de los Estados Unidos Mexicanos en el 2009, implicó la transformación del derecho a la protección de datos como excepción al derecho de acceso a la información, y la positivización del derecho al acceso, rectificación, cancelación, oposición y protección de los datos personales como patrimonio jurídico inherente a las personas. ${ }^{10}$

A nuestro entender, la reforma en comento considera cinco ejes fundamentales en materia de datos personales, en directa relación con los titulares de este derecho, a saber:

10 El artículo 16 de la Constitución mexicana establece: "Nadie puede ser molestado en su persona, familia, domicilio, papeles o posesiones, sino en virtud de mandamiento escrito de la autoridad competente, que funde y motive la causa legal del procedimiento.

Toda persona tiene derecho a la protección de sus datos personales, al acceso, rectificación y cancelación de los mismos, así como a manifestar su oposición, en los términos que fije la ley, la cual establecerá los supuestos de excepción a los principios que rijan el tratamiento de datos, por razones de seguridad nacional, disposiciones de orden público, seguridad y salud públicas o para proteger los derechos de terceros."
1. Protección de datos personales;

2. Acceso a sus datos personales;

3. Rectificación de datos personales;

4. Cancelación de sus datos personales; y,

5. Oposición en el uso de sus datos personales.

La protección de los datos personales entre particulares conlleva cambios radicales en la concepción de derechos entre y frente a los mismos: las garantías individuales (actuales derechos humanos a partir de la reforma del artículo $1^{0}$ de la Constitución mexicana), ${ }^{11}$ mediante las cuales y según la teoría clásica solo eran oponibles frente a violaciones de la autoridad, se termina.

Del análisis del artículo 16 de la Ley Fundamental mexicana y de la Ley Federal de Protección de Datos Personales en Posesión de los Particulares (LFPDPPP), vale la pena destacar que el derecho a la protección de datos está inserto dentro de dos libertades fundamentales:

1. El derecho a la privacidad de las personas.

2. La libertad de la autodeterminación informativa comprendida dentro del derecho a la información.

La Suprema Corte de Justicia de la Nación ha definido con respecto a la privacidad, que:

11 Contrástese la reforma a la Constitución Política de los Estados Unidos Mexicanos de 10 de junio de 2011, publicada en el Diario Oficial de la Federación del Estado Mexicano. Disponible en http:// www.diputados.gob.mx/LeyesBiblio/ 
"Ias personas tienen derecho a gozar de un ámbito de proyección de su existencia que quede reservado de la invasión y la mirada de los demás, que les concierna sólo a ellos y les provea de condiciones adecuadas para el despliegue de su individualidad - para el desarrollo de su autonomía y su libertad-. A un nivel más concreto, la misma idea puede describirse apelando al derecho de las personas a mantener fuera del conocimiento de los demás (o, a veces, dentro del círculo de sus personas más próximas) ciertas manifestaciones o dimensiones de su existencia (conducta, datos, información, objetos) y al correspondiente derecho a que los demás no las invadan sin su consentimiento. En un sentido amplio, entonces, la protección constitucional de la vida privada implica poder conducir parte de la vida de uno protegido de la mirada y las injerencias de los demás, y guarda conexiones de variado tipo con pretensiones más concretas que los textos constitucionales actuales reconocen a veces como derechos conexos: el derecho de poder tomar libremente ciertas decisiones atinentes al propio plan de vida, el derecho a ver protegidas ciertas manifestaciones de integridad física y moral, el derecho al honor o reputación, el derecho a no ser presentado bajo una falsa apariencia, el derecho a impedir la divulgación de ciertos hechos o la publicación no autorizada de cierto tipo de fotografías, la protección contra el espionaje, la protección contra el uso abusivo de las comunicaciones privadas, o la protección contra la divulgación de informaciones comunicadas o recibidas confidencialmente por un particular." 12

12 Tesis aislada emitida por la Primera Sala de la Suprema Corte de Justicia de la Nación 1a. CCXIV/2009, visible en la página 277 del Semanario Judicial de la Federación y su Gaceta XXX, diciembre de 2009. También puede ser consultada en el sistema informático IUS bajo el número de registro 165823.
Así, la privacidad como núcleo fundamental del derecho a la protección de datos personales, se podría interpretar como el derecho que tienen los titulares de los datos que los identifican o los hacen identificables a que las demás personas de cualquier índole, no traspasen la esfera jurídica de protección de sus datos, salvo con su consentimiento. 0 si los responsables van a manipular los datos de un particular sin consentimiento de éste, debe existir fundamento legal expreso que los autorice.

El consentimiento es la expresión libre de la voluntad del titular del dato a que éste sea tratado por un responsable; dicho consentimiento deberá ser expreso cuando nos encontremos con la figura de datos sensibles. Existen algunas situaciones en que no será necesario el consentimiento por parte del titular del dato, pero casi siempre el responsable de las bases de datos es el Estado, por ejemplo, las relacionadas con seguridad pública o cuestiones fiscales, en las cuales los derechos de los titulares de los datos personales se ven restringidos.

Por otra parte, el Poder Judicial de la Federación ha establecido que:

"el derecho de la autodeterminación de la información supone la posibilidad de elegir qué información de la esfera privada de la persona puede ser conocida o cuál debe permanecer en secreto, así como designar quién y bajo qué condiciones puede utilizar esa información. En este contexto, el derecho a la intimidad impone a los poderes públicos, como a los particulares, diversas obligaciones, a saber: no difundir información de carácter personal entre los que se encuentran los datos personales, 
confidenciales, el secreto bancario e industrial y en general en no entrometerse en la vida privada de las personas; asimismo, el Estado a través de sus órganos debe adoptar todas las medidas tendentes a hacer efectiva la protección de este derecho". 13

Así las cosas, por autodeterminación informativa deberá de entenderse la capacidad con la que cuentan los particulares para elegir qué información de la que los identifica o los hace identificables podrá ser tratada por un responsable del manejo de datos y cuál no.

Es muy llamativo que el término autodeterminación informativa se entrelace de manera directa con el derecho a la información, pues éste implica la capacidad de los individuos para administrar la información (consentimiento o no), cuando menos en la parte que contenga sus datos personales y que esté en manos ajenas al titular.

La protección de datos personales compromete otras libertades que concretizan derechos específicos, como son el derecho a la intimidad y el derecho a la autodeterminación informativa. Por lo que para entender el núcleo fundamental del derecho humano a la protección de datos se tuvo que definir qué se entiende por estos dos últimos derechos, y la manera como convergen en un derecho autónomamente positivizado a nivel constitucional: el derecho a la protección, acceso, rectificación, cancelación y oposición de los datos personales.

13 Tesis aislada I.3o.C.695 C, de los Tribunales Colegiados, visible en la página 1253 del Semanario Judicial de la Federación y su Gaceta XXVIII, Novena Época, septiembre de 2008. También puede ser consultada en el sistema informático de tesis y jurisprudencias IUS, bajo el número de registro 168944
En la medida en que se conjunten correctamente estos derechos esenciales (autodeterminación informativa y derecho a la intimidad) se logrará que el derecho a la protección de datos personales sea legítimo, controlado e informado. La legitimidad consiste en el consentimiento libre por parte del titular del dato, para que sea tratado por un particular. El control implica que el particular defina, mediante el conocimiento informado, el alcance en la utilización del dato. La información sobre el manejo del dato incluye darle a conocer al titular del dato los derechos que tiene para manejar la información que lo identifica o lo hace inidentificable.

Por lo anterior, se puede llegar a la conclusión que la protección de los datos personales tiene la finalidad de regular su tratamiento legítimo, controlado e informado de cualquier información concerniente a una persona física identificada o identificable, a efecto de garantizar la privacidad y el derecho a la autodeterminación informativa de las personas. ${ }^{14}$

Para lograr que se respete la intimidad y la autodeterminación informativa, el segundo párrafo del artículo 16 de la Constitución Política de los Estados Unidos Mexicanos dispone que el titular del derecho a la protección de datos personales cuenta con las garantías de acceso, rectificación, cancelación y oposición de sus datos, pues a través de estas cuatro garantías éste puede definir y defender el alcance en el tratamiento de los mismos.

\footnotetext{
14 Contrástese con el artículo $1^{\circ}$ de la Ley Federal de Protección de Datos Personales en Posesión de los Particulares, disponible en http:// www.diputados.gob.mx/LeyesBiblio/
} 
El acceso a los datos personales significa que los titulares tienen derecho a acceder a sus datos personales que obren en poder del responsable, así como conocer el Aviso de Privacidad ${ }^{15}$ al que está sujeto el tratamiento. ${ }^{16}$

La rectificación de los datos personales implica que el titular de los datos que lo identifican o lo hacen inidentificable, tendrá derecho a modificarlos cuando sean inexactos o incompletos. ${ }^{17}$

El titular tendrá en todo momento el derecho a cancelar sus datos personales, lo cual comporta el cese del usufructo de los mismos por parte de la persona depositaria, una vez hayan concluido las acciones derivadas de la relación jurídica que funda el tratamiento de los mismos. ${ }^{18}$

Como oposición del uso de los datos personales se debe entender que el titular tendrá derecho en todo momento y por causa legítima a oponerse al tratamiento de sus datos. De resultar procedente, el responsable no podrá tratar los datos relativos al titular. ${ }^{19}$
El camino expresamente normado sobre el derecho de acceso, rectificación, cancelación, oposición y protección de los datos personales en el segundo párrafo del artículo 16 de la Constitución Política de los Estados Unidos Mexicanos implica un reenvío a la ley en general para su ejercicio, es decir, en la legislación secundaria se desarrollará el ejercicio de estos derechos consagrados a nivel constitucional, siendo la Ley de Protección de Datos Personales en Posesión de los Particulares la que regulará en lo específico dichos derechos.

La excepción a los derechos antes descritos, según el párrafo $2^{\circ}$ del artículo 16 de la Constitución Política mexicana son los siguientes:

\section{Seguridad nacional;}

2. Disposiciones de orden público;

\section{Seguridad;}

4. Salud pública; $y$,

\section{Proteger los derechos de terceros.}

Por seguridad nacional se debe entender, según el artículo 3 de la Ley de Seguridad Nacional:

"las acciones destinadas de manera inmediata y directa a mantener la integridad, estabilidad y permanencia del Estado Mexicano, que conlleven a la protección de la nación mexicana frente a las amenazas y riesgos que enfrente nuestro país, la preservación de la soberanía e independencia nacionales y la defensa del territorio, el mantenimiento del orden constitucional y el fortalecimiento de las instituciones democráticas de gobierno, el mantenimiento de la unidad de 
las partes integrantes de la Federación señaladas en el artículo 43 de la Constitución Política de los Estados Unidos Mexicanos, la defensa legítima del Estado Mexicano respecto de otros Estados o sujetos de derecho internacional, y la preservación de la democracia, fundada en el desarrollo económico social y político del país y sus habitantes". ${ }^{20}$

Disposiciones de orden público significa el conjunto de normas jurídicas que rigen la actividad pública de las personas en sociedad (derecho público), y se diferencian de las normas jurídicas que rigen a las personas en el ámbito privado (derecho privado). ${ }^{21}$

El concepto seguridad como excepción al ejercicio de los derechos de acceso, rectificación, cancelación, oposición y protección de datos personales es muy amplio, pues entran las distintas percepciones o concepciones del ámbito jurídico, por ejemplo: seguridad pública, seguridad jurídica, seguridad social, etc. Por lo que esta limitación al derecho es una puerta muy amplia, dada su indefinición específica.

Salud pública. Para analizar este concepto habrá que entender el derecho a la salud consagrado en el artículo $4^{\circ}$ de la Constitución Política, en su vertiente de salubridad general, que involucra el panorama general de salud del Estado. Por lo que la excepción al ejercicio del derecho a la protección de datos personales se

20 Contrástese el artículo 3 de la Ley de Seguridad Nacional, la cual puede ser cotejada en la siguiente dirección http://www.diputados.gob. $\mathrm{mx} /$ LeyesBiblio/pdf/LSegNac.pdf

21 Contrástese la tesis aislada I.9o.A.121a de los Tribunales Colegiados de Circuito, visible en el Semanario Judicial de la Federación XXXI, de marzo de 2010, en la página 3080 . Esta tesis también puede ser consultada en el sistema IUS bajo el número de registro 164885. actualiza cuando exista riesgo de mitigar la salubridad general. ${ }^{22}$

Proteger los derechos de terceros: esta excepción de la limitación a los derechos a partir de los derechos de otros ya ha sido explicada con antelación, por lo que en virtud de innecesarias repeticiones, se remite a la misma en la parte final del inciso 2 de este artículo.

Así las cosas, el derecho al acceso, rectificación, cancelación, oposición y protección de datos personales, pasa a ser patrimonio jurídico de las personas y, con ello, nace un derecho que es oponible a otros particulares, por lo que la relación del derecho a la protección de datos personales entre los particulares toma redimensiones reales.

La esencia de la constitucionalización de la protección de los datos personales frente a otro particulares viene a revolucionar el tema del manejo de la información, pues al ser este derecho autónomo y verificable frente a otros particulares, las relaciones se guían por el principio de legalidad, que para los particulares y en materia de protección de datos significará que las relaciones jurídicas a partir del manejo de datos personales se deberán ceñir a la legalidad emanada de los preceptos constitucionales antes citados.

22 Contrástese el artículo $4^{\circ}$ de la Constitución mexicana, la Ley General de Salud, y la tesis aislada del Poder Judicial de la Federación bajo el número de registro 167212, del sistema informático IUS de la Suprema Corte de Justicia de la Nación. 


\section{UNA CONCLUSIÓN A TRAVÉS DEL EJERCICIO DE LAS PERSONAS DE LOS DERECHOS DE ACCESO A LA INFORMACIÓN Y A LA PROTECCIÓN DE DATOS}

Hasta ahora hemos desarrollado: a) el derecho de acceso a la información a través de la concepción del Estado como garante, contenedor y usuario de la información; y b) el derecho de los particulares a la protección de datos personales como usuarios y contenedores de la información. Sin embargo hay muchos puntos en común desde las distintas posturas del manejo de la información, y el principal consiste en que tanto el acceso a la información como la protección de datos personales implican necesariamente el desarrollo del tema a través de la teoría de los derechos humanos.

En el caso mexicano, en la medida en que se comprenda la transición del derecho al acceso a la información al derecho a la protección de datos personales, se entenderán los núcleos fundamentales de ambos derechos y con ello sus alcances jurídicos. Además, el desarrollo de los derechos en la transición antes mencionada está inscrito bajo la perspectiva de los roles del Estado, los particulares y las personas, y enmarcado en la teoría general de los derechos humanos.

La manera en que ambos derechos se empatan y a la vez se limitan se da a través de la teoría de principios e interpretación de los derechos humanos. No sólo de los derechos de acceso a la información y a la protección de datos personales sino desde la perspectiva de los derechos en general, por lo que ambos derechos dependen del conjunto de los derechos humanos consagrados en el bloque de constitucionalidad normado a partir del artículo $1^{\circ}$ de la Constitución Política de los Estados Unidos Mexicanos.

Otra conclusión a la que podemos llegar consiste en que, si ya hemos admitido la interdependencia de los distintos derechos fundamentales para el ejercicio de los mismos, también se debe admitir la variedad de disciplinas en que éstos van a ser ejercidos y, por consiguiente, la diversidad de técnicas que se necesitan para su ejercicio.

Lo anterior cobra importante relevancia no sólo jurídica sino científica en general. En el aspecto jurídico la interdependencia de las ramas ius publicita y ius privatista es evidente, pues a pesar de ser un tema directamente relacionado con los derechos fundamentales, también implica necesariamente la adecuación de los mismos al derecho privado para un correcto ejercicio, dado que influye indistintas relaciones de corte particular. La interdependencia con temas tecnológicos en el manejo de la información resulta también evidente. La multidisciplinariedad en las distintas ramas del conocimiento es trascendental para el ejercicio de los derechos humanos.

Así las cosas, el derecho al acceso a la información y el derecho a la protección de datos son interdependientes en la regla y la excepción de los derechos humanos y para su correcto ejercicio habrá que tener en cuenta esas bases, de 
lo contrario no se podrá definir correctamente el núcleo del derecho y ello imposibilitará su ejercicio.

\section{Fuentes Legislación}

Constitución Política de los Estados Unidos Mexicanos.

Ley Federal de Transparencia y Acceso a la Información Pública Gubernamental.

Ley Federal de Protección de Datos Personales en Posesión de los Particulares.

Ley de Seguridad Nacional.

\section{Criterios Judiciales}

Tesis aislada PLX/2000, del Pleno de la Suprema Corte de Justicia de la Nación, visible en el Semanario Judicial de la Federación XI, Novena Época, de abril de 2000. También puede ser consultada en la base de datos de tesis y jurisprudencia IUS de la Suprema Corte de Justicia de la Nación bajo el número de registro 191967.
Tesis aislada $1^{\mathrm{a}}$. CLXXXVIII/2009, emitida por la Primera Sala de la Suprema Corte de Justicia de la Nación, publicada en el Semanario Judicial de la Federación y su Gaceta XXX, de noviembre de 2009, página 401. También puede ser consultada en la base de datos de tesis y jurisprudencia IUS de la Suprema Corte de Justicia de la Nación bajo el número de registro 166037.

Tesis aislada emitida por la Primera Sala de la Suprema Corte de Justicia de la Nación, 1 a. CCXIV/2009, visible en la página 277 del Semanario Judicial de la Federación y su Gaceta XXX, diciembre de 2009. También puede ser consultada en el sistema informático IUS bajo el número de registro 165823.

Tesis aislada I.3o.C.695 C, de los Tribunales Colegiados, Novena Época, visible en la página 1253 del Semanario Judicial de la Federación y su Gaceta XXVIII, septiembre de 2008. También puede ser consultada en el sistema informático de tesis y jurisprudencias IUS bajo el número de registro 168944.

Tesis aislada I.9o.A.121a de los Tribunales Colegiados de Circuito, visible en el Semanario Judicial de la Federación XXXI, marzo de 2010, página 3080. También puede ser consultada en el sistema IUS bajo el número de registro 164885. 